\title{
Alberto Mussa e a tradução
}

\author{
Pere Comellas ${ }^{1}$
}

\begin{abstract}
Alberto Mussa é, segundo ele próprio, um autor singular no panorama literário brasileiro contemporâneo, no que o realismo é hegemônico: "A literatura brasileira tem o vício do realismo. Não que eu seja contra. Admiro uma série de livros realistas. Mas, num conjunto literário onde você observa que todos trabalham com o mesmo princípio, isso é um problema" (Mussa, 2010, p. 12). Supõe-se, portanto, que Mussa se inscreve num dos múltiplos ramos da fiç̧ão fantástica: para ele, a matéria fundamental da literatura é a própria literatura, toda ela, sem fronteiras nem geográficas nem temporais nem estéticas:
\end{abstract}

Não consigo trazer, para os livros, as minhas experiências pessoais. Então, procuro escrever a partir de um problema qualquer. É meu processo de criação. Encontro algum problema literário, alguma história que li, algum romance que me inspira, e digo: "Puxa, eu poderia dar a isso um tratamento x" (Mussa, 2010, p. 12).

É, portanto, uma literatura que não só exclui o "eu" mas também a realidade tal como entendida pelo sentido comum: daí a sua necessária inscrição no fantástico. O próprio Mussa afirma que onde encontrou modelos para esse tipo de escrita foi primeiro em Bioy Casares e logo a seguir em seu parceiro Jorge Luis Borges - provavelmente o maior representante dessa tendência literária (maior em termos de radicalidade e de qualidade e impacto).

Contudo, uma literatura da releitura é necessariamente uma literatura da reescrita. E a forma mais genuína de reescrita, a mais perfeita, é a tradução. ${ }^{2}$ Não por acaso a teoria e a prática da tradução ocuparam algum espaço na obra de Borges. Apesar de não ter formulado uma teoria da tradução como tal, ${ }^{3}$ Borges falou nela com alguma frequência e

\footnotetext{
${ }^{1}$ Doutor em linguística, tradutor e professor da Universitat de Barcelona, Barcelona, Espanha. Email: perecomellas@ub.edu

${ }^{2}$ Para Lefevere (1992), a edição, a crítica, a historiografia ou a antologia são outras formas de reescrita.

3 "Existe también la difundida creencia de que Borges contribuyó a cierta teoría de la traducción y de que sus ensayos sobre estos temas forman algún tipo de corpus revelador. Sin embargo, si se leen con atención estos textos ('Las dos maneras de traducir', el prólogo a la versión de Néstor Ibarra de $E l$ cementerio marino de Paul Valéry, 'Las versiones homéricas' o 'Los traductores de las 1000 y una noches') los conceptos relacionados con el métier resultan en extremo exíguos” (Gargatagli, 2009).
} 
especialmente com muita perspicácia, de tal modo que a brevidade de seus comentários (o corpus geralmente analisado limita-se a quatro ensaios, um conto e talvez algum prólogo, além das entrevistas) produziu uma muitíssimo mais extensa rede de análises, críticas e exegeses.

Não tenho indício nenhum de que Alberto Mussa adote as ideias de Jorge Luis Borges sobre a tradução. Minha hipótese é que Mussa compartilha algumas dessas ideias porque compartilha essencialmente a visão da literatura do autor argentino, e a escolha dessa estética, a inscrição no fantástico da releitura e da reescrita, conduz quase que sem remédio a certa concepção da tradução.

Não há dúvida quanto à importância da tradução na obra de Mussa. Desde seu primeiro livro, a coletânea de contos Elegbara, publicada pela primeira vez em 1997," até o último, A primeira história do mundo (2014), suas ficções estão cheias de fontes e de vozes em múltiplas línguas, algumas vezes reproduzidas no idioma original, mas na maioria das vezes simplesmente "traduzidas": francês, tupi, árabe, alemão, quimbundo. Só no livro O movimento pendular (2006) é possível supor fontes em muitas línguas, visto que são aí reescritas ou reinventadas histórias de todos os tempos e dos quatro cantos do mundo.

Curiosamente, existe um contraste enorme na obra de Mussa entre a maciça presença de supostas traduções e as menções explícitas a essa atividade. Num autor que gosta tanto de enigmas, isso até pode ser mais um indício de sua centralidade. Ora, que as menções diretas sejam escassas não significa que Mussa não ofereça algumas pistas sobre o seu ponto de vista quanto à tradução. Minha hipótese aqui é, portanto, que, com efeito, Mussa tem uma visão pessoal do papel da tradução na literatura, e que essa visão aproxima-se com frequência à de Jorge Luis Borges.

\section{Os problemas da tradução: a tradução como recurso literário}

Algumas dessas poucas menções diretas à tradução na obra de Mussa dizem respeito aos "problemas de tradução". Com efeito, em várias ocasiões, o autor explicita incompreensões provocadas pela tradução, ou melhor, pela idiossincrasia das línguas, que por vezes estabelecem categorias diferentes sobre a realidade. Um exemplo:

\footnotetext{
${ }^{4} \mathrm{O}$ que a deixaria fora deste encontro, que focaliza a literatura produzida depois de 2000 . No entanto, segundo o próprio Mussa (2010), essa primeira edição "não teve repercussão nenhuma"; foi reeditada pela Record em 2005 e obteve uma recepção maior.
} 
O que não se pode aceitar sem crítica é, mais uma vez, a tradução do testemunho. Duvido que a moça tenha empregado a palavra sábado, como está nos autos. Os tupis nunca aceitaram o sistema europeu de divisão do mês em semanas, que é muito imperfeito. O mais provável é que Úrsula, no domingo 15 (quando Araribóia lhe apresentou o noivo que viria a recusar), tenha usado o termo qüecé, que vulgarmente se traduz por "ontem", para se referir aos eventos passados. O linguista do inquérito concluiu, assim, fosse sábado o dia em que Martim afirmara a intenção de matar o serralheiro (Mussa, 2014, p. 88).

E ainda:

O degredado não entendeu. Por que Tapiirim dizia que Lopo Eanes ainda seria seu bicho, se já o chamava de xeröó (meu bicho) há muito tempo? De fato, não fazia sentido. Refletiu mais uns momentos, observando a felicidade das pessoas diante dos insultos e agressões de Lopo Eanes, até que atinou com a armadilha em que aquela língua o fizera cair, impedindo que enxergasse a verdade desde o início. Porque de çöó - bicho formava-se corretamente xeçöó - meu bicho -. Era de um outro çöó - carne de bicho - ou de töó - carne de gente - que se derivava xeröó - minha carne, de gente ou de bicho; minha comida. Isso: Lopo Eanes era a comida de Tapiirim, sempre tinha sido a comida que Tapiirim ainda não comera e que faria questão de saborear (Mussa, 2005/1997, p. 25).

Esses exemplos, banais, permitem observar o interesse do autor pelas questões metalinguísticas: não se trata de alguém que, como acontece com frequência em culturas monolíngues e etnocêntricas, ignora completamente a existência da diversidade linguística e, portanto, faz com que todas as personagens, sejam da origem que forem, falem na sua língua. Mussa interessa-se pelas línguas e a sua imensa variabilidade, apesar de não estar sempre a explicitar a língua originária de suas histórias (uma atitude muito parecida à de Borges). $\mathrm{E}$ as línguas permitem também conferir diferenças culturais.

\section{A tradução como pretexto}

Uma segunda utilidade da tradução nos textos de Mussa é usá-la como pretexto para contar o que o autor quer através de histórias que 
supostamente são de outrem, isto é, sem atribuir a invenção da história completamente a si - recurso já usado inúmeras vezes e em obras tão prestigiadas como A peregrinação ou $O$ Quixote. ${ }^{5}$ É suposto que a tradução é sempre e necessariamente uma recriação, uma reinterpretação. Essa característica, habitualmente considerada uma das grandes debilidades da tradução, ou até a prova definitiva de sua imperfeição, de sua natureza secundária, corrompida, traidora, transforma-se nas mãos de autores como Mussa e Borges num recurso criativo extraordinário: na possibilidade de criar variantes, de dar nova vida a velhas histórias, de renovar narrativas gastas. Exemplo:

A versão clássica foi escrita em nheengatu, o tupi amazônico, pelo caboclo Maximiano José Roberto, descendente de índios tarianas e manaus; e publicada numa tradução italiana do já mencionado conde de Stradelli. Na variante original, ligeiramente diferente, o herói - Jurupari, filho de uma virgem - enfrenta verdadeira saga, tentando instituir num mundo bárbaro e anárquico as leis recebidas diretamente do Sol (Mussa, 2014, p. 135).

A variante original sempre é ligeiramente diferente. Essas "ligeiras" diferenças constituem o espaço de criatividade necessário que a tradução e outras formas de reescrita permitem, mas que escandalizam a concepção tradicional da tradução, que exige uma suposta fidelidade (com frequência identificada com a literalidade). ${ }^{6}$ Mussa finge adotar um registro acadêmico ${ }^{7}$ e, então, situa-se na periferia, cria uma personagem vitimizada pelo conhecimento ortodoxo por causa das suas teorias: "Críticos severos me acusaram de ter distorcido fontes ou mesmo forjado certos passos do processo" (Mussa 2014, p. 122).

Ou então: "Também são minhas todas as teorias etimológicas que alguns especialistas talvez julguem controversas. Prometo escrever, mais tarde, um enfadonho ensaio para demonstrá-las" (Mussa, 2014, p. 140).

\footnotetext{
${ }^{5}$ No segundo caso, é sabido que Cervantes, numa certa altura, afirma ser o texto todo uma tradução do árabe. Saliento o primeiro porque faz um uso específico muito interessante da voz do outro, sempre traduzida, para dizer coisas proibidas ou delicadas.

${ }^{6}$ O que reflete uma visão bastante simplista e até ingênua da tradução: a de que existe uma equivalência estática e independente dos contextos entre formas linguísticas diversas. Mesmo supondo que um determinado texto, especialmente literário, contenha um significado fixado (o que já é muito supor), a literalidade não é necessariamente a melhor forma de recriá-lo.

${ }^{7}$ Muitos dos textos de Mussa podem considerar-se "falsos ensaios". A questão da classificação genérica dos seus textos é bem interessante.
} 
De fato, boa parte de suas narrativas são, mesmo que não se diga, exemplos do uso da reescrita (a tradução, o comentário, o resumo etc.) como mecanismo criativo, isto é, como reivindicação do espaço que esses recursos abrem. Quando traduzimos, geramos um deslocamento que, na perspectiva de um Borges ou um Mussa não é, insisto, uma limitação ou um problema insolúvel, mas um universo de possibilidades literárias: Borges considerava a tradução um gênero literário, com suas restrições e suas exigências, mas não uma atividade subordinada. No entanto, tinha plena consciência, como a tem Mussa, de que essa não é a opinião hegemônica e, por isso, de vez em quando introduz algum recurso satírico para gozar sutilmente tanto a visão tradicional da tradução quanto o suposto rigor da academia.

Um exemplo acabado disso encontra-se no fragmento seguinte de $O$ trono da rainha Jinga (Mussa, 1999, p. 11):

Mendo Antunes - que, segundo ele próprio, aprendera a tal língua por suas andanças em terras de África - pôde ler, não sem dificuldade, o seguinte:

múcua njinda

cariapemba uabixe

uajibe tata uajibe mama

uajibe dilemba uajibe muebo

uajibe quitunda bunjila

ni dicata buquicoca

- Interessante - disse -, tenho a impressão de conhecer esses versos. Não me lembro de onde.

O próprio autor esclarece no final do romance que se trata de versos atribuídos a Zé Pelintra, que ele traduziu para quimbundo. Isto é, são versos originalmente em português compostos por uma entidade da umbanda e que Mussa usa como texto doutrinário duma suposta seita de origem africana com uma curiosa filosofia. A personagem do romance, Mendo Antunes, tem que retraduzir esses versos para português e, portanto, temos uma tradução de uma tradução, o que lembra muito o rodapé irônico de Borges no conto Pierre Menard, autor del Quijote, no qual ele fala de uma tradução literal para francês de uma tradução literal para castelhano de um livro francês. Ironicamente, Borges afirma não haver 
rastro desse livro. ${ }^{8} \mathrm{O}$ mesmo caso da narrativa central de $O$ enigma de Qaf (Mussa, 2004): uma história que o autor ouviu seu avô contar, um árabe que a tinha aprendido na sua língua e que a contava em português. Mas depois o autor diz discutir essa narrativa com os eruditos árabes e, portanto, teve de retraduzi-la para o árabe.

\section{A tradução como reprodução é impossível}

O conto de Borges que acabamos de citar é, precisamente, uma paródia do tradutor tradicional, aquele que visa rescrever um texto exatamente igual a outro texto preexistente. Borges apresenta um escritor francês do século XX, Pierre Menard, que pretende rescrever $O$ Quixote palavra por palavra. Não se trata de copiar, mas de reescrever. Menard, contra toda lógica, consegue seu objetivo e reescreve palavra por palavra dois capítulos, depois de um esforço titânico. É claro que, para a humanidade em geral, trata-se de um esforço inútil, visto que o resultado visível são dois capítulos idênticos aos de Cervantes, quer dizer, nada novo. Mas Borges não chega a ridiculizar essa pretensão, que no fundo é a do tradutor "fiel": além de inútil, é impossível, porque a leitura dos capítulos de Menard, só pelo fato de terem sido escritos não por um autor espanhol do século XVII, mas por um francês do XX, difere da do original. Isto é: como é o leitor quem contribui para a construção do significado de um texto, a alteração de uma das chaves interpretativas (a identidade do autor) altera também esse significado.

Mussa parece concordar com Borges também nesse aspeto. Em $O$ enigma de Qaf (Mussa, 2004, p. 22-23), aparece o seguinte fragmento:

Naquele tempo, os idiomas possuíam apenas verbos e substantivos, além de alguns pronomes e partículas menores. Yarub criou o adjetivo. Mas não se satisfez. "Quero uma língua infinita, em que cada palavra tenha infinitos sinônimos", é a frase clássica. E o trabalho infatigável de Yarub fez do árabe uma língua infinita. Mas havia um problema: substituía uma palavra por outra sem nunca conseguir obter o mesmo sentido, de maneira precisa, exata, inequívoca. Surgia sempre alguma ideia nova, algum matiz, algo que escapava à acepção original. Foi o caso de jâmal (camelo),

\footnotetext{
${ }^{8}$ Borges brinca com a ideia de que uma tradução literal de uma tradução literal deveria ser a restituição exata do texto original, se o ideal da tradução no sentido tradicional pudesse ser atingido. Na prática isso nunca acontece, mas, se assim fosse, seria uma "tradução" invisível, claro.
} 
inicialmente um pretenso sinônimo de jamal (beleza); ou de bayt (casa), que Yarub tentou forjar como equivalente de bayd (ovo). Infortunadamente, esses insucessos caíram no conhecimento popular e inspiraram os primeiros vagabundos que começaram a fazer poemas. Yarub armou homens para trucidá-los. Mas não teve êxito: o vício da poesia tinha contaminado as mulheres; e elas passaram a ocultar os perseguidos, lançando sobre eles os próprios trajes de que se despiam. Yarub afrontou essa vergonha e manteve o cerco até que um dos poetas - Awad, dito também Awad compôs a sátira na qual um mesmo termo podia ter dois sentidos. Era o fim. - As palavras não são sequer sinônimas de si mesmas concluiu, de olhos baixos.

Yarub pretende achar termos distintos que tenham exatamente o mesmo significado, mas logo a empresa revela-se impossível. Como Yarub, o tradutor ideal tradicional pretende encontrar uma correspondência de significado exata com uma expressão em outra língua, ou seja, diferente. Mas nunca se sente totalmente satisfeito: sempre há "algum matiz, algo que escapa à acepção original". Mas justamente essa falha, essa insatisfação, dá origem à poesia! A literatura nasce no deslocamento de significados, na impossibilidade de reproduzir, na possibilidade de criar sempre um novo significado. Finalmente, nem sequer a mesma palavra parece ser capaz de conter um significado estável. Como o Quixote de Menard, a palavra ganha novos sentidos e é de todo impossível parar esse fenômeno: faz parte da linguagem humana, é uma característica da cognição humana. Portanto traduzir com a pretensão de querer extrair um suposto significado que aí está, para sempre, e reproduzi-lo exatamente com um material linguístico distinto é absurdo, porque não aportaria nada, e é absurdo, porque é impossível. A mesma conclusão a que Borges já chegara. $O$ fundamento de um uso da tradução como recurso criativo e não como subordinação sempre frustrada.

\section{Referências}

GARGATAGLI, Ana (2009). Borges: de la traducción a la ironia. 1611: Revista de Historia de la Traducción, Barcelona, n. 3, p. 1-5. Disponível em: https://goo.gl/5pcq7M. Acesso em: 4 out. 2016 
LEFEVERE, Andre (1992). Translation, rewriting, and the manipulation of literary fame. Londres: Routledge.

MUSSA, Alberto (2004). O enigma de Qaf. Rio de Janeiro: Record.

MUSSA, Alberto (2005/1997). Elegbara. Rio de Janeiro: Record.

MUSSA, Alberto (2006). O movimento pendular. Rio de Janeiro: Record.

MUSSA, Alberto (2007/1999). O trono da rainha Jinga. Rio de Janeiro: Record.

MUSSA, Alberto (2009). Meu destino é ser onça. Rio de Janeiro: Record.

MUSSA, Alberto (2010). Paiol Literário. Rascunho, Curitiba, n. 123, p. 12-13. Disponível em: https://goo.gl/s6xf3q. Acesso em: 4 out. 2016.

MUSSA, Alberto (2011). O senhor do lado esquerdo. Rio de Janeiro: Record.

MUSSA, Alberto (2014). A primeira história do Mundo. Rio de Janeiro: Record.

Recebido em janeiro de 2016.

Aprovado em junho de 2016.

\section{resumo/abstract/resumen}

\section{Alberto Mussa e a tradução}

Pere Comellas

A tradução - falsa ou autêntica - tem um papel importante na obra de Alberto Mussa. As presumíveis fontes dos seus romances incluem línguas como o árabe, o tupi, o francês ou o alemão, e o próprio autor ensaia também a tradução, num exercício que revela uma ideia muito borgeana da tradução: em literatura não há origem, só há reescrituras. A tradução na obra de Mussa é usada como pretexto, como recurso estético e narrativo, e também como evidência de uma concepção da linguagem humana como jogo e como fim em si mesmo. Para Mussa, como para Borges, traduzir não é repetir, mas recriar, e o tradutor, quer queira quer não, está condenado a ser poeta, visto que "as palavras não são nem sequer sinônimas de si mesmas".

Palavras-chave: tradução, linguagem, Alberto Mussa. 


\section{Alberto Mussa and translation}

\section{Pere Comellas}

Translation - whether real or not - has an important role Alberto Mussa's work. Among the presumed sources of his novels are languages such as Arabic, Tupi, French or German. Mussa is also a translator. In this activity, employs a very Borgean concept of translation: in literature there is no original, there are only rewritings. Translation, in the work of Mussa, is used as a pretext, as an aesthetic and narrative feature, as well as the evidence of a conception of human language as a game and as an end in and of itself. For Mussa - as well as for Borges - translating is not repetition, but recreation, and the translator is inevitably doomed to be a poet, since "words are not even synonymous with themselves".

Keywords: translation, language, Alberto Mussa.

\section{Alberto Mussa y la traducción}

Pere Comellas

La traducción - auténtica o falsa - desempeña un papel importante en la obra de Alberto Mussa. Las supuestas fuentes de sus novelas incluyen lenguas como el árabe, el tupí, el francés o el alemán, y el propio autor ensaya también la traducción, en un ejercicio que revela una idea muy borgiana de ésta: en literatura no existe origen, solamente rescrituras. Mussa usa en su obra la traducción como pretexto, como recurso estético y narrativo, y también como evidencia de una concepción del lenguaje humano como juego y como fin en sí mismo. Para Mussa, como para Borges, traducir no es repetir, sino recrear, y el traductor, tanto si quiere como si no, está condenado a ser poeta, ya que "las palabras no son ni siquiera sinónimas de sí mismas".

Palabras clave: traducción, lenguaje, Alberto Mussa. 